\title{
Transformação da Ação Mediada a partir da Ressignificação do Uso de Objetos Mediadores em Aulas do Ensino Superior
}

\section{Transformation of the Mediated Action by Re-Signifying the Use of Mediational Objects in Classes of Higher Education}

\author{
Leandro Antônio de Oliveira ${ }^{(1)}$ Brasil \\ Eliane Ferreira de Sá ${ }^{(10)}$ Brasil \\ Eduardo Fleury Mortimer ${ }^{\text {BD }}$ Brasil
}

Neste trabalho, investigamos como a utilização não usual de objetos mediadores por professores de Ciências Naturais do Ensino Superior possibilita novas significações para esses objetos durante o ensino em sala de aula. Os dados foram gerados a partir da gravação em vídeo de aulas de professores de Física e Química, ministradas em uma Instituição Federal de Ensino Superior. Inicialmente, com o auxílio do software NVivo11, produzimos mapas de episódios das aulas e construímos diagramas de mapeamento do uso de meios mediacionais pelos professores. Posteriormente, realizamos uma microanálise de fragmentos de alguns episódios nos quais os professores utilizaram os objetos, ressignificando-os nessas ações. Os resultados mostram que essas ressignificações são idiossincráticas, mas sempre ampliam e potencializam as qualidades dos meios mediacionais no ato de ensinar. Acreditamos que esses resultados trazem contribuições pontuais, mas importantes para o entendimento das aulas de professores universitários, além de propiciar a discussão e reflexão sobre o uso de diferentes recursos materiais que potencializam o trabalho do professor.

Palavras-chave: ressignificações; ação mediada; meios mediacionais; ensino superior; ensino de ciências.

In this article, we investigate how the unusual use of mediational objects by teachers of Natural Sciences in higher education creates new meanings for these objects during teaching in the classroom. The data were generated from the video recording of lessons of teachers of Physics and Chemistry, held in a Federal Institution of Higher Education. Initially, with the help of NVivo11 software, we produced episode maps of the lessons and diagrams mapping the use of mediational means used by the teachers. Subsequently, we performed a microanalysis of fragments of some episodes in which teachers use the objects, re-signifying them in these actions. The results show that these re-significances are idiosyncratic, but always amplify and potentiate the qualities of mediational means in the act of teaching. We believe that these results bring important contributions to 
the understanding of university teachers' lessons, as well as providing discussion and reflection on the use of different material resources that enhance the teacher's work.

Keywords: re-signification; mediated action; mediational means; higher education; science education.

\section{Introdução}

Em aulas da educação superior, professores usam objetos materiais com afinalidade de tornar mais claro os significados com os quais trabalham. Apoiados na ideia de que objetos materiais possuem essa dimensão mediacional na ação do professor, levamos em consideração os aspectos do que Wertsch (1998) denomina "meios mediacionais" ou, outros autores, "artefatos culturais" (por exemplo, Otero, 2003; Nakou, 2007; Tomasello, 2003).

Nesta pesquisa, nos referimos a esses objetos materiais principalmente como meios mediacionais. Essa denominação explicita nosso foco de análise nos meios mediacionais que possuem uma dimensão material e que são usados para auxiliar na construção de significados em ambientes de aprendizagem. Eles podem ser objetos comuns utilizados por professores em salas de aula, como o quadro de giz, projetor multimídia, retroprojetor, livros, tabela periódica, modelos concretos etc.

Tomamos como base, para nossas reflexões, alguns conceitos-chave de Werstch (1998), a fim de entender melhor a Teoria da Ação Mediada no processo de construção de significados. Essa teoria teve influências de outros pesquisadores. Um deles, para quem também damos atenção especial, apresenta o conceito de affordances atribuídas à ação (Gibson, 1986), importante para algumas análises que realizamos. Além disso, Wertsch (1998) apresenta dez propriedades que caracterizam a ação mediada, algumas delas com potencial para subsidiar a análise da ressignificação dos meios mediacionais, foco desta pesquisa. Contudo, acreditamos que os meios mediacionais utilizados por professores sempre apresentam novas possibilidades de significação ao serem usados. Nesse sentido, nos propomos a investigar como a utilização não usual que professores fazem de objetos mediadores possibilita suas ressignificações nas interações com os estudantes em sala de aula.

\section{O uso de meios mediacionais em salas de aula}

O uso de meios mediacionais pode ser caracterizado como ação mediada, no sentido exposto por Vigotski (2001) e aprofundado por Wertsch (1998). Este autor considera, como propriedade fundamental da ação mediada, a tensão irredutível entre o sujeito e os meios mediacionais com os quais ele atua. Wertsch (1998) sugere, como unidade de análise, o sujeito-atuando-com-meios-de-mediação, pois não há como separar agente e meio mediacional. Isso porque, na ação mediada é difícil perceber o que é exclusivamente do sujeito e o que é próprio do meio mediacional. Portanto, a exemplo do que Wertsch afirma, os agentes não se configuram isoladamente, mas sempre como 
indivíduos atuando com meios mediacionais.

Outra propriedade dos sujeitos-agindo-com-meios-mediacionais, destacada por Wertsch $(1998,1991)$, está relacionada ao conceito de affordances (potencialidades e limites), cunhado por Gibson (1986) para designar as propriedades ambientais disponíveis a certo indivíduo ou espécie animal, que permitem ou restringem a sua ação. Gibson caracteriza a ideia das affordances como sendo uma implicação sobre o modo como vemos as coisas, como chegamos até elas e o que fazemos, ou não, com elas. Segundo ele, o que isso sugere é que "a percepção visual que temos do ambiente serve ao comportamento e o comportamento é controlado pela nossa percepção" (Gibson, 1986, p. 223). Para Wertsch (1998), os indivíduos podem reconhecer e apropriar-se das affordances inerentes aos meios mediacionais, mas também podem limitar a sua ação tendo em vista o modo de uso desses mesmos meios.

Por fim, consideramos a propriedade da ação mediada denominada spin-off. Essa propriedade refere-se, dentre outras ideias, à noção de que os instrumentos de mediação são muitas vezes produzidos para outras finalidades que não as que estão sendo consideradas numa ação mediada específica. Wertsch (1998) considera que os usos de meios mediacionais se tornam "acidentes", com potencial inesperado capaz de transformar a ação. Tal spin-off pode ser, segundo Wertsch (1998), a norma e não a exceção quando se trata de meios utilizados na ação mediada que passaram por tal processo. Isso significa que a maioria das ferramentas culturais que nós utilizamos não foram projetadas para os fins em que estão sendo empregadas. Isso sugere que elas podem passar por processos de ressignificação ao longo do tempo.

Esse processo de ressignificação dos meios mediacionais, que tem por base a noção de spin-off, pode ser caracterizado como uma mudança nas funções que esses meios assumem numa ação específica. Neste artigo, analisamos fragmentos de aulas nas quais os professores usam objetos tradicionais de forma ressignificada. Por exemplo, um professor de Física usa um transferidor, objeto normalmente utilizado para medir ângulos, com função diferente desta, nesse caso, como um prisma para reproduzir a dispersão da luz em uma demonstração experimental.

Para analisar as ressignificações, tivemos que categorizar os recursos pedagógicos que são utilizados em sala de aula, de modo a permitir uma análise das mudanças de funções a que esses meios são submetidos no uso. Para isso, categorizamos e subcategorizamos esses meios de forma a deixar claro qual a função que eles desempenhavam numa ação mediada qualquer e qual função passaram a desempenhar quando foram ressignificados. Na próxima seção, apresentamos essas categorizações.

\section{Categorizando meios que fazem uso de suporte material e objetos mediadores}

Uma das propriedades que Wertsch (1998) considerada na ação mediada é a materialidade dos meios mediacionais. No entanto, quando abordamos a sala de aula como ação mediada, temos diferentes níveis de materialidade que devem ser 
explicitados para facilitar a análise. É claro que essa materialidade dos meios varia nas ações dos professores, dependendo do modo como eles utilizam tais recursos. Com isso, nos baseamos nas aulas que investigamos para gerar categorias relacionadas aos meios mediacionais. Para tanto, realizamos uma classificação dos meios mediacionais quanto à forma temporal como a materialidade se sustenta nas ações, que resultou nas seguintes categorias: meios mediacionais de materialidade instantânea; meios mediacionais de materialidade temporária e; meios mediacionais de materialidade permanente.

Wertsch esclarece o uso desses termos ao refletir sobre a propriedade que diz respeito à materialidade dos meios mediacionais. Segundo o autor, os aspectos da materialidade são importantes para a denominação do termo "artefatos" no sentido de artefatos históricos que permanecem existindo mesmo depois que os agentes que os usaram desapareceram (Wertsch, 1998). Além disso, Wertsch argumenta que existem meios mediacionais com materialidade instantânea (caso da linguagem falada) e aqueles que possuem uma materialidade permanente.

O caso mais relevante de uma ferramenta cultural aparentemente imaterial é a linguagem falada. Por isso, muitas vezes é mais fácil reconhecer a relevância dos objetos de linguagem escrita que continuam a existir mesmo quando eles não estão sendo empregados como meios mediacionais (por exemplo, um manuscrito que se encontra não utilizado em um tronco durante décadas) do que reconhecer a materialidade da linguagem falada. Ao contrário da linguagem escrita, a materialidade da linguagem falada parece evaporar após a existência de um momento, exceto para aqueles casos raros quando o discurso é gravado. No entanto, a materialidade é uma propriedade de quaisquer meios mediacionais (Wertsch, 1998, p.31).

Assim como sons produzidos ou imagens de vídeos reproduzidos em telas nas salas de aula, a fala é um meio mediacional que possui materialidade que desaparece instantaneamente. Desse modo, podemos categorizar esses meios como meios mediacionais de materialidade instantânea.

Pensamos, por outro lado, naqueles meios mediacionais que possuem materialidade permanente, isto é, meios mediacionais com características objetais que continuam a existir, mesmo que os agentes que os manipulam os abandonem na ação. Podemos exemplificar com os modelos moleculares, varas de apontar, objetos fixos no espaço físico etc. A esses recursos que, como afirmamos, continuam a existir mesmo após finalizada a ação, denominamos meios mediacionais de materialidade permanente.

Por último, destacamos os meios mediacionais de materialidade intermediária. Nessa categoria, se enquadram aqueles meios que não perdem a materialidade instantaneamente (como a fala), nem continuam a existir, após a ação (como modelo molecular), mas deixam de existir no decorrer da ação do sujeito, adquirindo nessa situação, uma materialidade intermediária.

Para exemplificarmos, podemos pensar na seguinte situação: ao ensinar usando o projetor multimídia, um professor projeta uma sequência de imagens e explica para os estudantes algum conceito. Segundo nossa categorização, a fala do professor pode ser 
classificada como meio mediacional de materialidade instantânea, porque ela desaparece instantaneamente após ser proferida. Por sua vez, as inscrições projetadas normalmente possuem materialidade mais duradoura do que a fala. Contudo, ao projetar as inscrições com o uso do projetor multimídia (considerado aqui com materialidade permanente), o professor normalmente muda os slides com frequência, no mesmo intervalo em que a comunicação acontece. Nesse contexto, consideramos as imagens e textos contidos nos slides como meios mediacionais de materialidade intermediária.

Nos casos de ressignificação de meios mediacionais que estudamos neste artigo, os professores fazem uso de meios de materialidade permanente. Por isso, focamos nosso olhar na manipulação de recursos dessa categoria por eles. Porém, observamos que os meios de materialidade permanente apresentavam diferentes affordances no ambiente das salas de aula que se relacionavam com suas características apresentadas durante a manipulação. Nesse contexto, sentimos a necessidade de uma subcategorização desses meios.

Essa subcategorização foi realizada com vistas às capacidades de modificação do ambiente, causadas nas ações. Com essa percepção, subcategorizamos os meios mediacionais de materialidade permanente em meios que fazem uso de suporte material ${ }^{1}$ e objetos mediadores.

Alguns exemplos do que denominamos meios que fazem uso de suporte material são aqueles com funções de projeção, escrita e leitura. Considerando essas três funções observadas nas ações dos professores podemos, novamente, subdividir e categorizar os meios que fazem uso de suporte material em três tipos: meios que fazem uso de suporte material de projeção, meios que fazem uso de suporte material de escrita e meios que fazem uso de suporte material de leitura.

Como observamos, os meios que fazem uso de suporte material de projeção são aqueles utilizados como meios e suportes materiais específicos para projetar imagens, desenhos, textos, tabelas diagramas etc. Dentre os mais utilizados em salas de aula, podemos citar os artefatos tecnológicos usados por professores ${ }^{2}$, como retroprojetor, projetores multimídia, datashow, dentre outros.

Os meios que fazem uso de suporte material de escrita são aqueles recursos utilizados, tanto por professores quanto por estudantes, como meios de inserção de informações por meio da escrita, incluindo também o desenho de imagens, equações, fórmulas e outros artefatos culturais representados manualmente. Dentre os mais utilizados nos ambientes de aprendizagem, citamos o quadro de giz (ou quadro branco), cadernos, folhas de papel, cartazes manuscritos e outros.

1 Os meios que fazem uso de suporte material não são considerados meios mediacionais em sua essência. Porém, na investigação que se seguiu, por serem recursos utilizados para apresentar meios mediacionais que são projetados, escritos ou com os quais se realizam leituras, consideramos que eles são necessários para que ocorram as ações com esses meios mediacionais. Por isso, levamos em consideração esses meios nos diagramas construídos. 2 Para esses meios que fazem uso de suporte material de projeção, levamos em consideração a tela de projeção, o aparelho projetor e, por vezes, computadores e auxiliares, podendo ser denominados no conjunto como aparatos de projeção. 
Por último, destacamos os meios que fazem uso de suporte material de leitura, como os que fazem parte da ação de sujeitos, no sentido de serem utilizados como mediadores de textos prontos, imutáveis, diferentemente dos meios que fazem uso de suporte material de escrita. Como exemplos, destacamos os livros, fichas de resumo, anotações, tabela periódica, etc.

A outra subcategoria que propusemos foi nomeada objetos mediadores. Objetos mediadores são aqueles recursos com potencial de modificar o meio quando utilizados pelos sujeitos. Nós classificamos os objetos mediadores como: dêiticos; prototípicos; metrológicos; ressignificados e experimentais/fenomenológicos.

Os objetos mediadores dêiticos são aqueles utilizados para dar ênfase ou colocar em evidência algum elemento de interesse. Como exemplos, temos vara de apontar, ponteira laser ou algum objeto semelhante a esses utilizado para tal função.

Os objetos mediadores prototípicos são aqueles objetos utilizados para representar alguma entidade, amplificada ou reduzida, normalmente por meio de modelos concretos ou analógicos. Como exemplos para a categoria de modelos concretos, temos: terrários, globos terrestres, modelos de corpo humano, modelos de esqueletos, modelos planetários, etc. Como exemplos de modelos analógicos, temos principalmente os modelos moleculares dos tipos vareta e bola-vareta.

Objetos mediadores metrológicos são aqueles objetos que têm a função de realizar medidas em ambientes de aprendizagem. Muito comuns em laboratórios de ciências, podemos citar os termômetros, amperímetros, manômentros, relógios, réguas, bússolas, balanças, vidrarias graduadas de laboratório, transferidores etc.

A categoria denominada objetos mediadores ressignificados é uma categoria diferente de objetos mediadores. Eles recebem essa denominação porque são objetos usados na ação com funções diferentes daquelas para as quais eles foram criados (Oliveira, Sá, \& Mortimer, 2017) o que se aproximam da propriedade spin-off da ação mediada (Wertsch, 1998).

Além disso, essa categorização também deve ser pensada em termos das formas de ação dos professores com os meios mediacionais. Isto porque, dependendo do modo como o sujeito age com o meio mediacional, o objeto molda e explicita a função para a qual ele está sendo usado, naquele momento. Por exemplo, o retroprojetor, geralmente, é utilizado para projetar imagens, como discutido no trabalho de Moro et al. (2013), no qual uma professora de Química Orgânica utilizou o retroprojetor para projetar imagens contidas nas transparências. Neste contexto, o retroprojetor poderia ser categorizado como meio que faz uso de suporte material de projeção. Em outro trabalho, Oliveira, Sá e Mortimer (2017) apresentam uma situação de ensino na qual um professor de Física usou o retroprojetor, que se constituiu, na ação, como aparato experimental capaz de reproduzir o fenômeno de polarização da luz. Nesse caso, o retroprojetor pode ser entendido como objeto mediador ressignificado, pois a sua função na ação mediada mudou.

Por último, chamamos a atenção para a subcategoria de objetos mediadores 
que contempla os aparatos experimentais. A esse agrupamento, denominamos objetos mediadores experimentais/fenomenológicos. Os objetos mediadores experimentais/ fenomenológicos são aqueles que, em grupo ou isoladamente, se configuram como meios mediacionais de materialidade permanente, manipuláveis e capazes de produzir na ação um experimento com função de reproduzir algum fenômeno.

Desse modo, demonstramos esquematicamente, na Figura 1, as subdivisões e categorizações que realizamos baseadas, principalmente, nas ações de professores com os meios mediacionais de materialidade permanente que observamos nesta investigação.

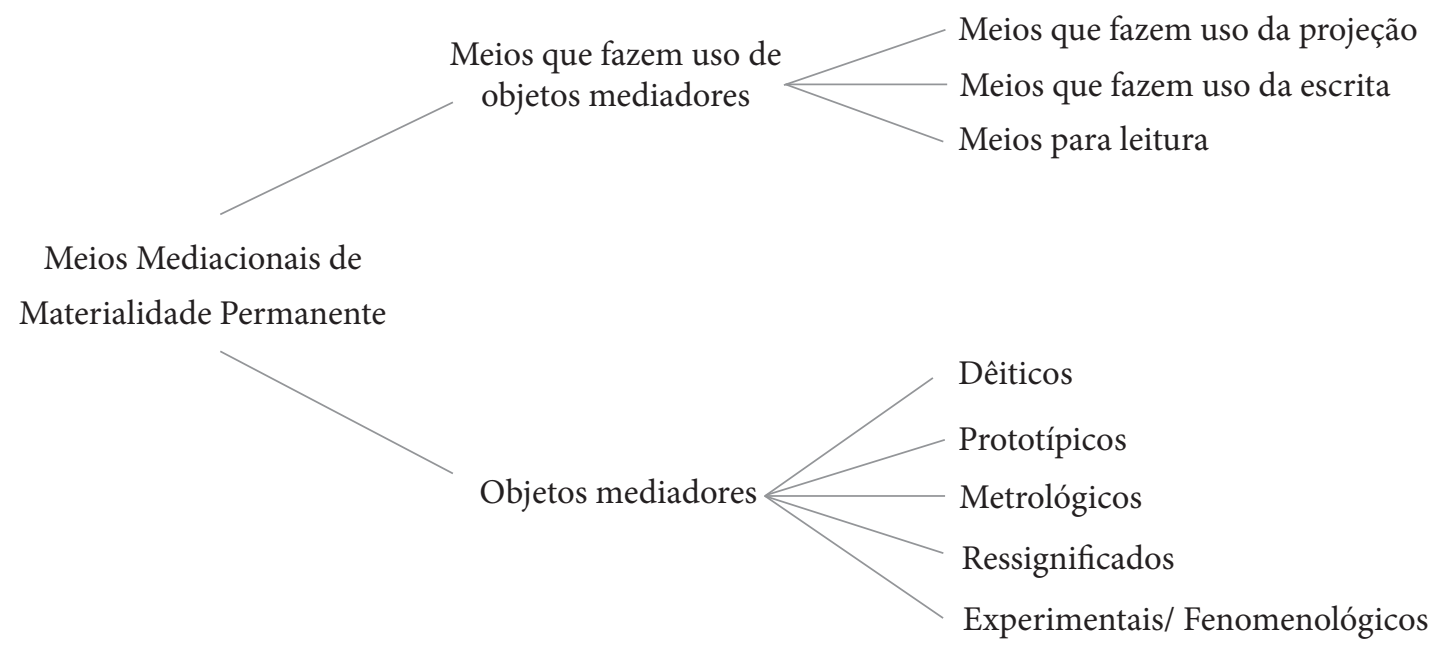

Figura 1. Diagrama de categorização e subcategorização dos Meios Mediacionais

De posse dos referenciais teóricos apresentados neste trabalho, podemos inferir que as ressignificações que os professores realizam no uso de objetos mediadores abre uma perspectiva importante para estudar a ação mediada em sala de aula por meio de suas propriedades. Nesse sentido, ao ressignificar objetos, o professor traz na sua prática exemplos concretos da propriedade denominada por Wertsch (1998) de spin-off. Considerando a especificidade da sala de aula, que tem um discurso próprio, podemos entender em que condições se processa esse spin-off, que ganhos ele traz para a ação mediada do professor, e que potencialidades têm os objetos disponíveis no ambiente da sala de aula para que essas transformações ocorram.

A partir dessas considerações, procuramos responder, neste trabalho, às seguintes questões de pesquisa: Como objetos mediadores são ressignificados por professores de Química? Como essas ressignificações produzidas podem transformar a ação mediada?

\section{Metodologia}

Para a investigação aqui relatada realizamos uma busca, no banco de dados que serve ao nosso grupo, por videogravações de aulas que demonstrassem situações de uso, por professores, de recursos materiais com potencial inovador ou que apresentassem alguma característica, não usual, de ações em ambiente universitário. A partir da 
busca, selecionamos aulas que apresentavam situações nas quais quatro professores universitários utilizavam algum meio mediacional de modo a produzir ressignificações sobre seu uso.

Foram identificadas situações promovidas pelo professor Elvis ${ }^{3}$ em uma aula de Física, pela professora Daiane em uma aula de Química Geral, pela professora Aline em uma aula de Química Orgânica e pelo professor Mateus em uma de Química Inorgânica.

$\mathrm{Na}$ Figura 2 apresentamos uma descrição geral e simplificada do perfil dos professores e o contexto das aulas analisadas.

\begin{tabular}{|l|c|l|l|}
\hline Professor & Tempo de magistério & Disciplina & Temática \\
\hline Elvis & 25 & $\begin{array}{l}\text { Fundamentos de Óptica } \\
\text { e Oscilações de Ondas }\end{array}$ & Atividade óptica \\
\hline Aline & 22 & Química Orgânica & $\begin{array}{l}\text { Estabilidade de compostos } \\
\text { monocíclicos }\end{array}$ \\
\hline Daiane & 07 & Química Geral & Geometria molecular \\
\hline Mateus & 35 & Química Inorgânica & Isomeria de complexos inorgânicos \\
\hline
\end{tabular}

Figura 2. Tempo de experiência no magistério dos professores, disciplinas e temática das aulas selecionadas

Todas as aulas foram filmadas na mesma universidade. Após selecionarmos as aulas, realizamos a etapa de macroanálise. Nela, assistimos a todas as aulas selecionadas e com o auxílio do software Nvivo11, construímos o mapa de episódios de cada uma delas. Esses episódios são, de acordo com Mortimer e colaboradores, "um conjunto coerente de ações e significados produzidos pelos participantes em interação, que tem início e fim claros e que pode ser facilmente discernido do episódio precedente e do subsequente" (Mortimer, et al., 2007, p. 61). Essa construção foi importante para termos uma visão mais geral do que estava sendo discutido e feito em cada aula. Para dividir as aulas em episódios, levamos em consideração os temas e conceitos introduzidos e finalizados pelos professores, as suas ações com os recursos, bem como as interações entre eles e os estudantes. Além de possibilitar uma visão geral de quais temas foram abordados pelos professores, bem como as suas ações com os recursos, os mapas de episódio possibilitaram visualizar o conjunto global dos dados e informações da aula para, posteriormente, auxiliar em nossas microanálises e na explicitação dos nossos resultados.

Após a produção dos mapas de episódio, realizamos a etapa de microanálise. Essa etapa foi importante para identificarmos aqueles episódios nos quais professores usavam meios mediacionais de modo ressignificado. Com os episódios selecionados, realizamos a fragmentação de trechos em que essa ressignificação dos recursos acontecia. Desse modo, realizamos a descrição desses fragmentos complementando-os com a transcrição da fala dos professores para posteriormente analisarmos as ressignificações e classificá-las, de acordo com a categorização apresentada na Figura 1. A seleção e

3 Para mantermos as identidades dos professores no anonimato, atribuímos a eles nomes fictícios, como sugerem os regimentos éticos da pesquisa em Ciências Humanas. 
fragmentação dos episódios, bem como a transcrição da fala dos professores foram ações metodológicas importantes para observarmos especificamente tanto as ações não usuais dos professores com os objetos quanto para compreendermos como eles construíam as explicações dos conceitos nesses momentos. Por sua vez, para a categorização, cada um dos autores analisou independentemente os fragmentos selecionados e se reuniram para discutir cada resultado de modo a verificar o grau de concordância e dirimir possíveis inconsistências. Se houvesse alguma discrepância na análise individual, reassistíamos em conjunto o fragmento, discutindo-o à luz dos referenciais e das categorias de meios mediacionais propostas até chegarmos a um resultado consensual. A seguir, descrevemos brevemente as aulas e os fragmentos.

\section{Resultados}

Os fragmentos selecionados apresentam ações dos professores do Ensino Superior com meios mediacionais na sala de aula, durante a explicação dos conceitos científicos pertencentes às unidades didáticas. Descrevemos primeiramente, de forma geral, as aulas dos professores, o fragmento selecionado e por último, a transcrição do discurso verbal produzido nos momentos de compartilhamento e produção de novos significados. No decorrer das transcrições, consideramos necessário fazer explicações relacionadas a algumas passagens da fala porque os professores utilizam com frequência expressões dêiticas, como "isso", "aquilo" etc., que não adquirem sentido na transcrição, pois só têm sentido quando consideradas no contexto audiovisual em que se encontram.

\section{Primeiro fragmento: Aula de Física - uso do aparato experimental pelo professor Elvis}

Iniciamos com o professor de Física, Elvis, que utilizou um aparato experimental em uma aula ministrada para estudantes do curso de Física da universidade, no âmbito da disciplina Fundamentos de Óptica e Oscilações de Ondas. Essa aula foi filmada em 2011 e teve a duração de 01 hora e 33 minutos. A unidade didática da qual a aula foi selecionada tratava do tema atividade óptica, em especial, a polarização da luz.

No decorrer da aula, o professor utilizou três recursos para compartilhar significados com os estudantes: o projetor multimídia, o quadro branco e um aparato experimental.

O projetor multimídia foi utilizado por Elvis para resumir e destacar alguns conceitos abordados nas aulas anteriores e aqueles que ele abordava durante a aula. $\mathrm{O}$ quadro branco, por sua vez, foi utilizado para desenhar um esquema para representar o que ocorre durante fenômeno de polarização dielétrica. Por último, como aparato experimental, o professor utilizou um retroprojetor e dois filtros polarizadores, no qual desenvolveu uma demonstração experimental sobre polarização da luz.

O fragmento que foi escolhido para a análise teve duração de 05 minutos e 12 segundos. Nele, as ações de Elvis com o aparato experimental atraíram nossa atenção. Em tais ações, Elvis introduzia, no retroprojetor, materiais que possuem atividade óptica. 
Devido ao desenvolvimento tecnológico, o retroprojetor vem perdendo espaço no cotidiano das salas de aula, e praticamente tem sido substituído por meios de projeção mais sofisticados, como o projetor multimídia. Entretanto, no caso da aula de Elvis, esse recurso foi utilizado paralelamente com o projetor multimídia. Porém, os dois suportes de projeção possuíam funções bem distintas. Isso porque Elvis utilizou o projetor multimídia com a finalidade de projetar textos e imagens, enquanto o retroprojetor foi utilizado para reproduzir e projetar o fenômeno da polarização da luz.

O fenômeno de polarização da luz acontece da seguinte forma: A luz branca - por exemplo, a luz solar - é um tipo de luz não polarizada, pois quando ela é emitida, seus raios se propagam em todos os planos. Isso ocorre porque a luz branca (policromática) é composta de ondas eletromagnéticas que vibram em infinitos planos perpendiculares à direção de propagação da luz. Por outro lado, a luz polarizada é aquela que vibra em apenas um plano e pode ser obtida passando a luz natural por um polarizador. Essa situação é usada, por exemplo, para estudar a atividade óptica dos materiais.

Para realizar a demonstração experimental o professor utilizou, além do retroprojetor, um conjunto de materiais colocados sobre filtros polarizadores e explorou os fenômenos reproduzidos para cada um deles. Esses materiais são uma peça retangular de acrílico, um transferidor meia-lua, uma fita adesiva transparente, um pedaço de papel celofane amassado e um pedaço de mica. Para melhorar a visibilidade do experimento, Elvis o projetou na tela em frente ao quadro branco, por meio do retroprojetor.

Alguns desses materiais são comuns no cotidiano escolar, como o transferidor meia-lua, a fita adesiva e o papel celofane. Porém, Elvis explorou outras funções nesses objetos, diferentes das usuais justificando da seguinte maneira:

Isso aqui é um transferidor fabricado em acrílico / também de plástico / quando você olha isso aí / sobre luz polarizada / você vê também regiões onde antes não passava luz / nem a luz do polaróide estava cruzada e aqui / nitidamente está passando luz de frequências diferentes e em regiões diferentes / isso aqui então / é um tipo de atividade óptica / que depende da frequência da luz / quer dizer / diferentes cores são geradas / tem a ver com a direção de polarização / porque o campo elétrico é gerado em ângulos diferentes.

Elvis fez vários giros na lâmina polarizada em cima do transferidor de forma a evidenciaroaparecimento odesaparecimento dofenômeno físico, na projeção(Figura3).
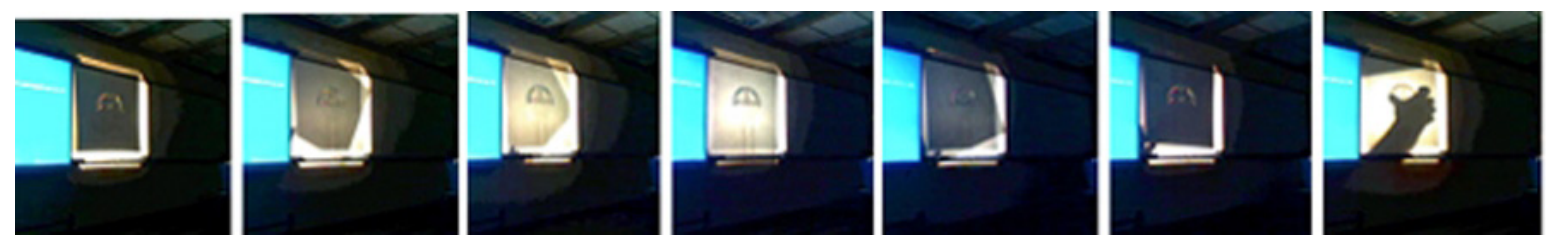

Figura 3. Uso do aparato experimental por Elvis para verificar a atividade óptica no transferidor

Após a ação com o transferidor no aparato experimental, Elvis utilizou uma placa de vidro onde foram coladas sucessivas camadas de fita adesiva transparente, de modo a formar duas figuras: um raio e a uma estrela. Elvis explicou o uso da fita adesiva da 
seguinte maneira:

A fita adesiva também é um polímero / o material usado na fabricação dele é esticado / deformado / e aí / apresenta também atividade óptica / quando você olha isso sobre uma luz polarizada / independente aqui da direção de polarização da luz / você não vê efeito nenhum / porém se você usar os dois polaróides cruzados / ((veja)) aí que maravilha né / aí você vai ver diferença / a luz que atravessa o material / tá / dependendo se antes não estava passando luz porque os campos elétricos estão cruzados / agora passa em certas regiões / luzes de frequências diferentes. Então você tem uma atividade óptica / quer dizer / tá passando luz. É porque a direção de polarização da luz foi mudada / ao passar / ao atravessar esse material / esse giro na direção de polarização depende da espessura / depende do tanto que a luz atravessa um material / esse material que produz cores diferentes e também apresenta uma dependência com a frequência. Quer dizer / diferentes cores de luz / diferentes frequências são geradas de ângulos diferentes / por isso / então / o efeito de cor.

A fita adesiva é constituída por uma superfície coberta por uma substância colante, sendo usada para juntar duas superfícies, mas também é um polímero que apresenta atividade óptica. Desse modo, o professor utilizou este objeto com a função de evidenciar o mesmo fenômeno óptico de polarização obtido com o transferidor, só que agora, formando múltiplas cores que se alternavam no desenho projetado, dependendo do giro feito nos filtros polarizadores. Como anteriormente, ele fez giros sucessivos nos filtros de modo a evidenciar o aparecimento e desaparecimento da atividade óptica (Figura 4).
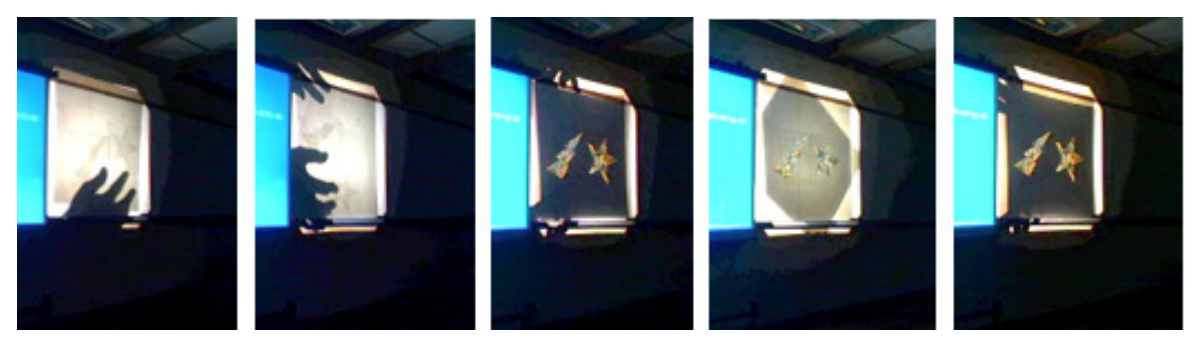

Figura 4. Uso do aparato experimental, por Elvis, para verificar a atividade óptica na fita adesiva

O professor também realizou ações semelhantes usando um pedaço de papel celofane amassado e pedaços de mica, material cristalino natural que se forma por meio de lâminas, discutindo o mesmo fenômeno de polarização.

\section{Segundo fragmento: Aula de Química Orgânica - uso de uma folha de papel para representar o caderno do(a) estudante}

Esse fragmento foi retirado da aula de Química Orgânica da professora Aline, ofertada a estudantes do primeiro período dos cursos de mestrado e doutorado da pós-graduação em Química. Essa aula foi filmada em 2012 e teve a duração de aproximadamente 4 horas. A aula filmada fez parte de um conjunto de aulas de revisão de temas abordados nos cursos de graduação, importantes para as discussões posteriores 
nas disciplinas da pós-graduação. O tema do episódio selecionado fazia parte de Estereoquímica e Aline estava relembrando as diferentes formas de representação dos compostos orgânicos.

Nessa aula, Aline utilizou um modelo molecular do tipo vareta para representar estruturas químicas que ela tinha projetado na tela de projeção, usando o retroprojetor. Ela usou também o quadro de giz para desenhar estruturas químicas, além de objetos disponíveis no ambiente de sala de aula.

No fragmento específico, que teve duração de 02 minutos e 33 segundos, Aline enfatizou o uso de uma regra e de uma contra-regra para manipular as estruturas químicas na representação de Fischer. Ela já havia demonstrado essa regra e contraregra antes, usando uma representação que estava projetada na tela.

A Projeção de Fischer é um método relativamente simples e muito utilizado em química orgânica para representar compostos de carbono quiral. Com ela, é comum a representação de átomos de carbono tetraédricos e seus substituintes em duas dimensões que são desenhados, por exemplo, no papel ou no quadro. Esse método consiste no desenho da molécula em forma de cruz (Figura 5a), com o carbono quiral no ponto de interseção. As linhas horizontais representam as ligações que, na representação da molécula, em perspectiva (Figura 5b), estão na direção do observador, isto é, na frente do plano da página (linhas em cunha cheia). Por sua vez, as linhas verticais representam as ligações que se afastam do observador, por trás do plano da página (cunhas tracejadas). As representações em cunhas cheias e tracejadas devem ser arranjadas dessa forma para facilitar sua conversão em projeções de Fischer. Essa representação auxilia na avaliação das rotações de uma projeção de Fischer que podem ou não mudar a configuração absoluta da molécula (denominadas R ou S) em questão. Desse modo, as rotações permitidas para uma projeção de Fischer são aquelas correspondentes à rotação de ângulos de 180 graus. Nessa situação, a representação em projeção permanece na mesma configuração. Porém, se a molécula for retirada do plano do papel, em um rebatimento, no qual se inverte a posição dos átomos ligados aos traços horizontais, a configuração da molécula em Projeção de Fischer se inverte. Giros dessa natureza alteram a configuração de $(\mathrm{R})$ para $(\mathrm{S})$.

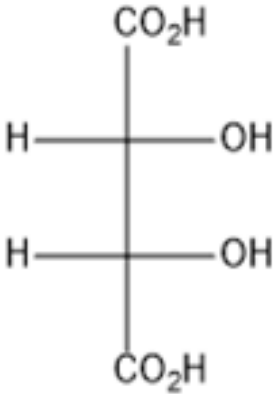

Figura 5a

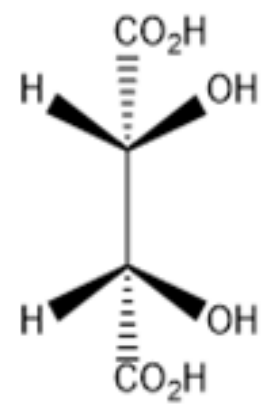

Figura $5 b$

Figura 5. Representações da molécula de glicose em Projeção de Fischer (5a) e em perspectiva $(5 b)$ 
Nesse fragmento, Aline procurou enfatizar como os estudantes poderiam verificar, em seus cadernos, os possíveis giros nas representações em Projeção de Fischer. Para isso, ela olhou para a mesa a sua frente, se aproximou dela e pegou uma folha de papel. Ela afirmou que a folha de papel representava o caderno do(a) estudante. Nesse caderno, ela representou uma molécula imaginária com a qual iria demostrar a regra e a contraregra. Ela, então, colocou a folha sobre o suporte do retroprojetor, apoiou a mão aberta sobre a folha e realizou dois giros que indicavam ângulos de 180 graus. Na sequência, ela apoiou a mão sobre a folha e rebateu a palma e as costas da mão, evidenciando que aquele tipo de giro não poderia ser realizado. Este fragmento está ilustrado na Figura 6, sendo a transcrição da fala da professora apresentada em seguida.
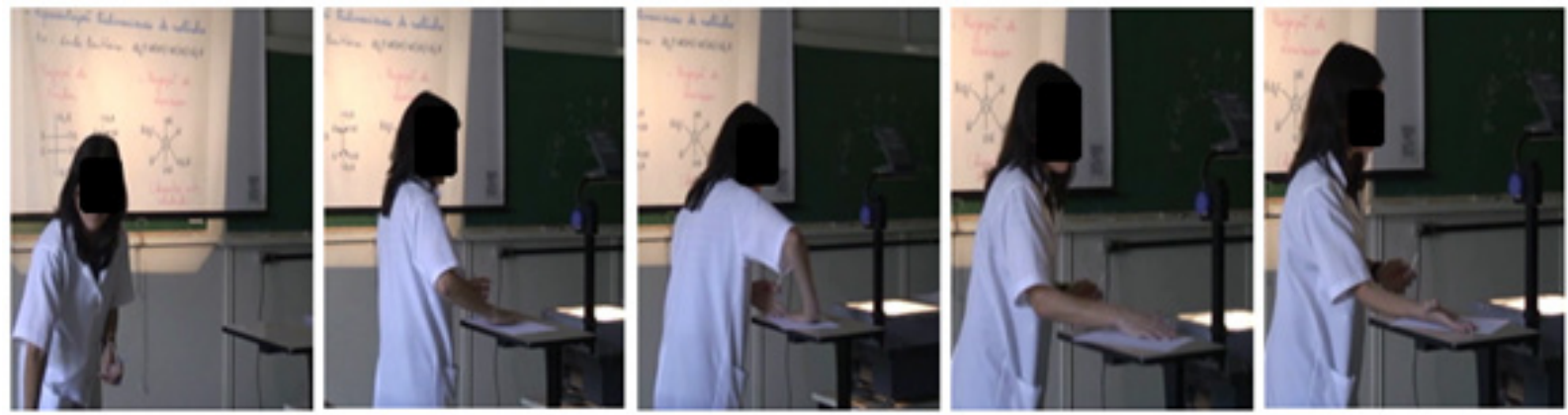

Figura 6. Uso da folha de papel, por Aline, para evidenciar a regra e a contra-regra para ensinar a manipulação das representações químicas em projeção de Fischer

Então qual a forma que eu tenho para trabalhar? Quando eu quero trabalhar com esses modelos eu tenho que fazer isso aqui ó ((usando a folha)) / Vamos supor que eu estou aqui com o caderno / eu só posso fazer isso aqui ó ((girando dessa forma)) / Não posso rebater ((como faço com a mão)) / É óbvio que se eu estiver com o modelo na mão eu posso fazer o que eu quiser / Cheguei aqui girei ligação ((do eixo principal)) / Posso. Isso eu posso / O que eu não posso é fazer isso aqui ((rebater dessa forma)) no papel e achar que é a mesma coisa quando eu estiver analisando / aí eu só faço isso aqui ((girando em 180 graus no plano da mesa como faço com a folha)) está claro isso? Porque esse é o erro mais frequente que as pessoas às vezes trazem lá da graduação e confundem.

\section{Terceiro fragmento: Aula de Química Geral - uso de uma folha de papel em complemento ao modelo molecular pela professora Daiane}

Nesse fragmento, a professora Daiane utilizou uma folha de papel em complemento ao modelo molecular, em uma aula cuja unidade didática se referia à geometria molecular. Essa aula foi ministrada para estudantes do curso de Química e foi filmada em 2017, tendo duração de aproximadamente 01 hora e 40 minutos.

Geometria molecular é o conteúdo da Química no qual se estuda como os átomos estão organizados espacialmente em uma molécula. Dependendo da quantidade e dos átomos que a compõem, uma molécula pode assumir várias formas geométricas, sendo as principais geometrias: linear, angular, trigonal plana, piramidal e tetraédrica.

Para ensinar a geometria de diferentes moléculas, Daiane utilizou quatro 
recursos: o projetor multimídia, o quadro de giz, modelo molecular e uma folha de papel. O projetor multimídia foi utilizado pela professora para projetar conceitos-chave importantes para tratar dos números de coordenação, dos arranjos e das geometrias possíveis, além de projetar imagens em 2D de estruturas moleculares. Daiane usou o quadro de giz para desenhar algumas estruturas, demarcar vetores e evidenciar pares de elétrons que são determinantes para avaliar a disposição espacial dos átomos nas moléculas. O modelo molecular foi utilizado para demonstrar, em 3D, as estruturas moleculares e para avaliar os arranjos e as geometrias possíveis. Por último, observamos que Daiane usou a folha de papel para complementar o modelo molecular. Isto porque a folha, um objeto utilizado normalmente para escrever ou imprimir, foi usado por ela para representar um plano, auxiliando a visualização das ligações que, em uma molécula em geometria trigonal plana, ficam no mesmo plano.

No fragmento que escolhemos para descrever e analisar, que teve duração de 01 minuto e 15 segundos, Daiane pegou o modelo molecular com três varetas unidas pelo vértice, que representava uma estrutura em geometria trigonal plana. Ela explicou que uma molécula composta por quatro átomos, três deles ligados ao átomo central, na qual não há pares de elétrons não ligantes, se configura em uma geometria trigonal plana. Para evidenciar que as ligações e os átomos, nesse tipo de geometria se localizam no mesmo plano, Daiane se aproximou da mesa, pegou uma folha de papel e apoiou o modelo molecular sobre a folha, enfatizando as posições dos átomos e das ligações no plano. A Figura 7 ilustra algumas ações de Daiane, seguida da transcrição da fala da professora nesse contexto.
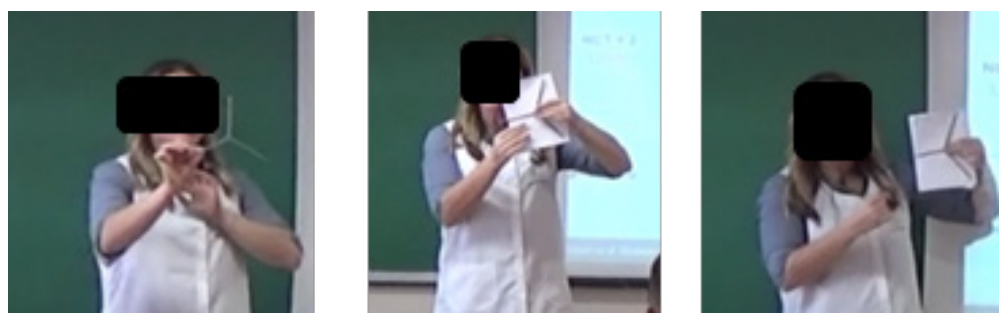

Figura 7. Uso da vareta de apontar e do modelo molecular, por Daiane, para evidenciar o eixo imaginário e as ligações em axial e em equatorial

Se a gente pensar em três conjuntos de elétrons / qual será a disposição espacial deles / para que eles fiquem o mais afastados possível? Vai ser um arranjo trigonal plano ((da molécula)) / isso aqui ó / Quer ver? Deixa eu pegar uma folha de papel / Então ó / vocês vão ter num plano / três conjuntos de elétrons / Está dando para ver ((a posição dos átomos no plano))? E eles formam exatamente a estrutura ou a figura de um triângulo / tá ((dando para ver))? E a gente vai ter aí esses conjuntos de elétrons separados / aqui ó. São três ângulos de 120 ((graus)) / tá ? É o que tá aqui ó / ((Geometria)) trigonal plana e a gente vai ter os ângulos de 120 ((graus)). 


\section{Quarto fragmento: Aula de Química Inorgânica - uso de pedaços de fita adesiva em complemento ao modelo molecular pelo professor Mateus}

O fragmento a seguir evidencia como o professor de Química Inorgânica, Mateus, utilizou um modelo molecular adaptado com pedaços de fita crepe, em uma aula cuja unidade didática tratava da Introdução ao Estudo de Complexos, ministrada em 2017. A turma em questão era composta por estudantes do curso de Farmácia e a aula escolhida teve duração aproximada de 01 hora e 40 minutos. Ao ensinar os conceitos envolvidos nesta unidade didática, o professor Mateus discutiu sobre o subtema Isomeria de complexos de coordenação.

O isomerismo é um aspecto característico tanto de compostos orgânicos quanto de inorgânicos. Compostos que possuem a mesma fórmula molecular, mas diferentes arranjos estruturais são chamados de isômeros. Vários tipos de isomeria ocorrem entre os compostos de coordenação. Quando, além disto, os agregados possuem as mesmas ligações, mas diferem no arranjo espacial destas ligações, são chamados de estereoisômeros. Ao ensinar os conceitos envolvidos na temática, Mateus discutiu subtemas como: Estrutura e simetria dos compostos, tipos de ligantes usuais e regras de nomenclatura. Para compartilhar significados com os estudantes de Farmácia, Mateus utilizou quatro recursos: o projetor multimídia; o quadro de giz; folhas de resumo, pedaços de fita crepe e modelos moleculares dos tipos vareta e bola-vareta.

Mateus fez uso do projetor multimídia no sentido de projetar figuras de moléculas, textos com conceitos químicos, tabelas e esquemas. No quadro de giz, Mateus basicamente desenhava estruturas de complexos em diferentes geometrias e resolvia exercícios. As folhas de resumo continham textos com informações sobre contextos históricos de produção de medicamentos, a história de vida dos cientistas que os produziram e aplicações desses medicamentos na área da saúde. Por último, o professor utilizou o modelo molecular do tipo vareta para representar compostos inorgânicos em 3D e tratar de conceitos relacionados às suas respectivas geometrias em cada representação.

Além de constituir o modelo molecular com as varetas que o compõem, Mateus utilizou outro material, de modo a complementar o objeto: pedaços de fita crepe. A fita crepe é um tipo de fita adesiva utilizada geralmente para juntar duas superfícies. Nesse caso, em específico, os pedaços de fita crepe foram utilizados para representar as ligações em pontes de ligantes bidentados no complexo, função semelhante às das varetas convencionais dos modelos moleculares. Esses ligantes bidentados, comuns em complexos inorgânicos, interferem diretamente na configuração isomérica dos compostos, dependendo em quais posições da estrutura eles se encontram.

No fragmento que selecionamos, que ocorreu em 2 minutos e 7 segundos, Mateus abordou a estabilidade de complexos inorgânicos. Nossa atenção se voltou para a utilização de modelos moleculares para tratar de ligantes quelatos em estruturas inorgânicas. Com esse objeto mediador, o professor evidenciou que entre alguns átomos, existem ligações parecidas com pontes, semelhantes a arcos, que indicam ligações anelares. Após tratar 
dessas características, Mateus abandonou o modelo molecular do tipo bola-vareta e pegou um modelo molecular do tipo vareta. Esse modelo, maior do que o primeiro utilizado por ele, apresentava uma adaptação, não usual, feita por Mateus, com pedaços de fita crepe. Nesse caso, em específico, os pedaços de fita crepe foram utilizados para representar as ligações em pontes entre dois átomos ligantes no complexo. Isso interferia diretamente na estabilidade do composto, evidenciada por meio de dados contidos em uma tabela que foi projetada no aparato de projeção, como explicado pelo professor durante a comunicação. Algumas imagens que representam esse fragmento podem ser observadas na Figura 8.
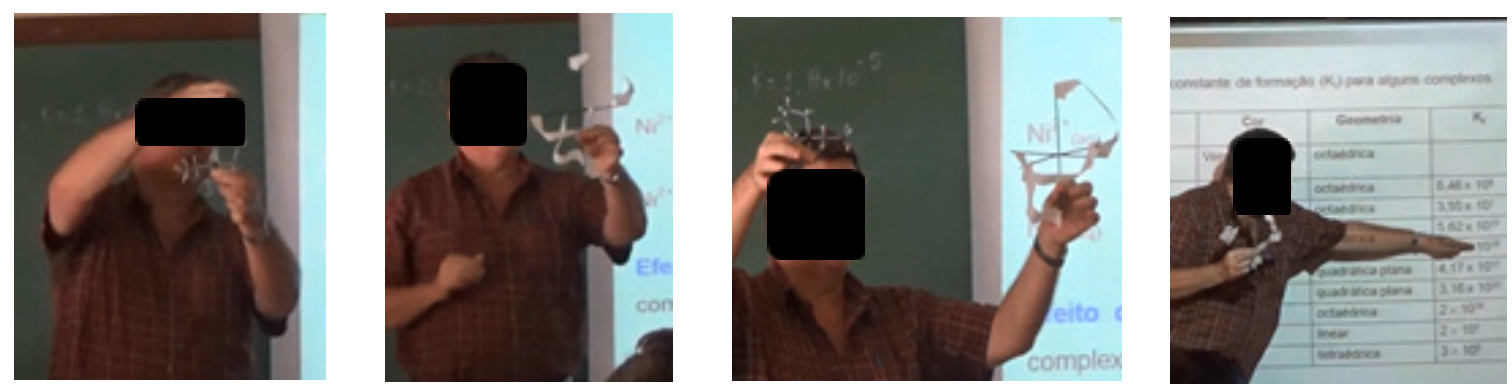

Figura 8. Uso da fita crepe em complemento ao modelo molecular e de outros recursos, por Mateus, para evidenciar anéis em modelos moleculares do tipo vareta

O discurso de Mateus encontra-se transcrito abaixo:

Então eu falei com vocês que / na hora que a gente vai começar a desenhar os complexos / porque na aula que vem / a gente vai começar a trabalhar com isomeria. Então / nós vamos fazer o desenho de uma maneira simplificada / então toda essa parte aqui / com carbono / nós vamos substituir por um arco. Então nós vamos colocar só os átomos doadores para indicar que se trata de um ligante bidentado / e portanto / vai formar um anel. Então / nós vamos usar uma representação esquemática / usando um material bem simples. Dessa forma aqui ((representada pelo modelo molecular do tipo vareta)) então eu tenho que / isso ((pedaços de fita)) é a representação esquemática que nós vamos usar a partir de agora / disso ((dos ligantes bidentados)). Então para simplificar / para ficar mais fácil da gente ver / e aqui / então essa fita crepe corresponde àquele átomo que eu tinha mostrado na aula passada / nos desenhos que tinha aparecido / indicando que aqui eu tenho uma formação de um anel. Então / tem um anel aqui / outro aqui / e outro aqui e que a geometria ela é octaédrica. Então / esse é o complexo formado. Então eu vou formar os anéis com formação de quelato. Ele ((o complexo)) tem que se reorganizar para achar uma melhor maneira possível de distribuir esses ligantes ao redor do átomo central / para minimizar as repulsões / para poder aumentar a estabilidade do complexo / e o resultado final vai formar um complexo que é muito estável. 


\section{Discussão}

Com exceção da professora de Química Geral, Daiane, que possui 7 anos de experiência no magistério, os outros professores (Elvis, Aline e Mateus) possuem mais de 20 anos de carreira docente. Observamos que, durante suas aulas, eles fizeram uso de uma variedade de meios mediacionais de materialidade permanente para promover a comunicação científica com os estudantes. Acreditamos que a escolha desses recursos está relacionada com as especificidades de cada aula, das suas experiências em ministrar aulas no Ensino Superior e também sobre a sensibilidade em considerar possíveis dificuldades dos estudantes na aprendizagem de determinados conceitos científicos. Além disso, parece que todos eles planejaram as aulas de modo a torná-las mais dinâmicas e pautadas em ações envolvendo os meios mediacionais.

De um modo geral, quando focamos nosso olhar sobre os meios mediacionais de materialidade permanente, como os objetos mediadores e os meios que fazem uso de suportes materiais, percebemos que os recursos tiveram participação determinante nas ações que se seguiram durante as aulas.

Sobre as ações específicas de cada professor, nos fragmentos selecionados, várias reflexões podem ser feitas. Isso porque observamos que a produção de sentidos em cada situação foi idiossincrática, dependente dos modos como as ações eram estabelecidas. Para discuti-las, analisamos as situações que observamos nos fragmentos descritos das aulas de cada um dos professores.

Primeiramente nas aulas do professor Elvis, despertou nossa atenção o modo como ele utilizou o aparato experimental (retroprojetor e filtros polarizadores) para reproduzir o fenômeno da atividade óptica com os objetos: transferidor meia-lua, fita adesiva, papel celofane e mica.

O retroprojetor é um artefato cuja função original é a de projetar imagens, tendo sido muito utilizado em salas de aula para projetar textos e figuras. Entretanto, essa função foi sendo substituída paulatinamente pelo projetor multimídia, que cumpre tal função com mais qualidade e mais versatilidade. Por exemplo, nesse novo recurso de projeção, os textos dos slides são produzidos no próprio computador, as imagens são retiradas da internet com qualidade e nitidez e existe a possibilidade de usar animações e vídeos. Entretanto, o retroprojetor conserva a função de projetar fenômenos, que o projetor multimídia não cumpre. Uma maneira de fazer isso, com o projetor multimídia, seria por meio da filmagem do fenômeno. Entretanto, com o retroprojetor, a imagem projetada é real, está acontecendo no momento da ação, enquanto a imagem projetada pelo projetor multimídia é virtual, pois o fenômeno aconteceu em outro momento. Acreditamos que o retroprojetor ainda não se tornou obsoleto porque ele tem essa função de projetar fenômenos de interesse das ciências naturais. Por isso, mesmo sendo substituído pelo projetor multimídia, suas funções não foram esgotadas por esse outro recurso.

No caso do uso específico do retroprojetor por Elvis no fragmento descrito, o recurso permitiu ao professor produzir na sala de aula fenômenos ópticos que ele estava 
apresentando conceitualmente, por meio de textos e fórmulas, no projetor multimídia. Além disso, nos chama a atenção a função que ele atribuiu ao uso do transferidor e da fita adesiva em suas ações.

Pensando nas classificações apresentadas anteriormente na Figura 1, o retroprojetor deixa de ter a função de um suporte material para projeção e passa a se constituir como um aparato experimental capaz de reproduzir o fenômeno de atividade óptica. Nesse caso, o retroprojetor se constituiu tanto como um objeto mediador experimental/fenomenológico quanto como um objeto mediador ressignificado. Nesse contexto, podemos afirmar que, como há uma forma nova de mediação, ampliam-se as possibilidades de compartilhamento de significados quando o retroprojetor é usado dessa forma na aula. Desse modo, a ação de Elvis com o retroprojetor e os objetos de acrílico produziram ressignificações na aula e potencializaram as qualidades desses objetos no ato de ensinar.

O mesmo pode ser pensado ao se analisar as funções preestabelecidas do transferidor meia-lua e da fita adesiva, por exemplo. No caso do transferidor meia-lua, esse objeto é muito utilizado na atividade de resoluções de problemas de geometria, pois auxilia, por exemplo, na medição de ângulos de figuras. Nesse sentido, ele normalmente pode ser classificado como objeto mediador metrológico. Por outro lado, a fita adesiva, pelas funções normalmente atribuídas a ela de juntar superfícies, não possui uma classificação no esquema proposto por nós. Porém, na aula de Elvis, esses dois recursos materiais se configuram como objetos importantes para complementar o aparato experimental no sentido de reproduzir o fenômeno de polarização da luz. Desse modo, podemos classificá-los, em função de sua utilização nas ações de Elvis, como objetos mediadores ressignificados.

O aparato experimental não é estático e também sofreu modificações ao longo da ação. Por exemplo, como resultado do uso do transferidor, apareceu na projeção um espectro com todas as cores. A representação de um fenômeno por meio de um conjunto de objetos expandiu as formas de mediação e construção de significados.

Sobre as ações da professora Aline com os recursos observados no fragmento descrito, o que despertou nossa atenção foi o uso diferenciado que ela fez de uma folha que ela buscou no momento da ação para representar o caderno do(a) estudante. É interessante que, a partir da observação de outras aulas, constatamos que Aline sempre recorreu a objetos e outros elementos que constituem o ambiente de sala de aula ressignificando-os. Entendemos que o fato de ela tomar uma folha de papel e dizer que ela representava um caderno do(a) estudante reforça a interação que a professora procurou ter com os estudantes, pois há uma movimento de aproximação da folha com o objeto que o estudante utiliza no seu dia-a-dia: o caderno.

A folha, normalmente um meio usado como suporte material de escrita, passa nesse caso a representar um caderno no qual está desenhada a fórmula de Fischer. Portanto, nesse caso, a folha pode ser considerada um objeto mediador ressignificado. Nesse sentido, os gestos que Aline realizou indicando que é possível girar a fórmula no 
plano, mas não pode levantá-la do plano do papel, deixaram claro que regra e contraregra devem ser observadas no uso das fórmulas de Fischer.

A ação de Daiane com a folha de papel aconteceu no sentido a dar complementaridade ao uso do modelo molecular. Isto porque a folha de papel, um objeto utilizado normalmente para escrever, auxiliou na discussão das posições de ligações químicas e átomos que necessitavam da visualização de um plano que continha os quatro átomos constituintes de uma molécula em geometria trigonal plana.

Notamos que, pelas funções para as quais as folhas são criadas, poderíamos classificá-las como meios que fazem uso de suporte material de escrita. Porém, nas ações de Daiane, a ressignificação produzida pelo uso da folha para representar um plano sugeriram que houve uma transformação na sua função, passando a mesma a se constituir como um objeto mediador ressignificado.

Por último, evidenciamos as ações de Mateus com o modelo molecular complementado-o com os pedaços de fita crepe. Como já mencionamos, a fita crepe possui a função de unir superfícies. Porém, para explicar os compostos com ligantes bidentados, Mateus usou o modelo molecular, já complementado com os pedaços de fita crepe que representavam os anéis em complexos com ligantes bidentados. Após essa ação inicial, Mateus agiu somente com o modelo molecular adaptado para evidenciar os possíveis planos de simetria, utilizando a mão para isso. Na sequência, o professor adaptou o modelo de forma a representar outro composto, a imagem-espelho de um complexo que também estava projetado na tela. Dessa maneira, o que podemos concluir é que os pedaços de fita crepe, em isolado, tiveram uma função na ação (representar os anéis em ponte dos ligantes bidentados) diferente daquela para qual a fita foi criada (juntar superfícies). Objetos com essa função não foram categorizados na Figura 1, porque não são geralmente utilizados com uma finalidade pedagógica. Porém, devido às novas funções que a fita apresentava na ação (representar uma peça que não existe no modelo molecular referente às pontes), podemos categorizá-la como objeto mediador ressignificado.

Nesse contexto de ressignificações promovidas pelos quatro professores de Ciências, para que pudéssemos categorizar os meios mediacionais como objetos mediadores ressignificados (aparato de projeção, transferidor, fita adesiva, folhas de papel e fita crepe) foi necessário avaliarmos as funções que esses recursos possuíam antes e durante as ações produzidas pelos professores, quando em uso dessas ferramentas. Somente por meio de uma análise comparativa, foi possível concluir que aqueles recursos estavam produzindo diferentes significados nas ações que descrevemos dos professores.

Visualizamos, na Figura 9, um resumo de como as ressignificações dos meios mediacionais causaram transformações em suas funções, nas aulas.

Essas ressignificações produzidas pelos professores se relacionaram com a propriedade que trata da transformação da ação mediada: os spin-off's. Quando Wertsch (1998) relata que a maioria das ferramentas culturais que nós empregamos não foi projetada para os fins para os quais estão sendo empregadas, ele busca em Vigotski 
(2001) a ideia-chave para esta afirmação: o significado construído e a ressignificação permitida pelos meios mediacionais. Nesses casos, em específico, consideramos que o espaço da sala de aula é um ambiente propício para que ocorram tais spin-off's porque, por ser um espaço de compartilhamento de significados, possibilita que o professor faça uso de artifícios para promover a construção de conhecimentos. Muitas vezes, para isso, ele pode mobilizar alguns recursos de modo a explorar as possibilidades que permitem ressignificar seu uso.

\begin{tabular}{|c|c|c|c|c|c|}
\hline Professor & Meios & $\begin{array}{l}\text { Função } \\
\text { do meio } \\
\text { mediacional } \\
\text { antes da ação } \\
\text { do professor }\end{array}$ & $\begin{array}{l}\text { Classificação } \\
\text { do meio } \\
\text { mediacional } \\
\text { antes da } \\
\text { ação } \\
\end{array}$ & $\begin{array}{l}\text { Função na ação do } \\
\text { professor }\end{array}$ & $\begin{array}{l}\text { Classificação do meio } \\
\text { mediacional durante } \\
\text { a ação }\end{array}$ \\
\hline \multirow{3}{*}{ Elvis } & Retroprojetor & $\begin{array}{l}\text { Projetar } \\
\text { textos e } \\
\text { imagens }\end{array}$ & $\begin{array}{l}\text { Meio que faz } \\
\text { uso de suporte } \\
\text { material de } \\
\text { projeção }\end{array}$ & $\begin{array}{l}\text { Reproduzir um } \\
\text { fenômeno por meio de } \\
\text { experimento }\end{array}$ & $\begin{array}{l}\text { Objeto mediador } \\
\text { experimental/ } \\
\text { fenomenológico e } \\
\text { Objeto mediador } \\
\text { ressignificado }\end{array}$ \\
\hline & $\begin{array}{l}\text { Transferidor } \\
\text { meia-lua }\end{array}$ & $\begin{array}{l}\text { Medir } \\
\text { ângulos } \\
\text { de figuras } \\
\text { geométricas }\end{array}$ & $\begin{array}{l}\text { Objeto } \\
\text { mediador } \\
\text { metrológico }\end{array}$ & $\begin{array}{l}\text { Ser usado como } \\
\text { material que possui } \\
\text { atividade óptica }\end{array}$ & $\begin{array}{l}\text { Objeto mediador } \\
\text { ressignificado }\end{array}$ \\
\hline & Fita adesiva & $\begin{array}{l}\text { Fixar } \\
\text { superfícies }\end{array}$ & $\begin{array}{l}\text { Sem } \\
\text { classificação }\end{array}$ & $\begin{array}{l}\text { Ser usado como } \\
\text { material que possui } \\
\text { atividade óptica }\end{array}$ & $\begin{array}{l}\text { Objeto mediador } \\
\text { ressignificado }\end{array}$ \\
\hline Aline & $\begin{array}{l}\text { Folha de } \\
\text { papel }\end{array}$ & Escrever & $\begin{array}{l}\text { Meio que faz } \\
\text { uso de suporte } \\
\text { material de } \\
\text { escrita }\end{array}$ & $\begin{array}{l}\text { Representar um caderno } \\
\text { que tem desenhada uma } \\
\text { fórmula de Fischer }\end{array}$ & $\begin{array}{l}\text { Objeto mediador } \\
\text { ressignificado }\end{array}$ \\
\hline Daiane & $\begin{array}{l}\text { Folha de } \\
\text { papel }\end{array}$ & Escrever & $\begin{array}{l}\text { Meio que faz } \\
\text { uso de suporte } \\
\text { material de } \\
\text { escrita }\end{array}$ & $\begin{array}{l}\text { Representar um plano } \\
\text { em complemento ao } \\
\text { modelo molecular }\end{array}$ & $\begin{array}{l}\text { Objeto mediador } \\
\text { ressignificado }\end{array}$ \\
\hline Mateus & Fita crepe & $\begin{array}{l}\text { Fixar } \\
\text { superfícies }\end{array}$ & $\begin{array}{l}\text { Sem } \\
\text { classificação }\end{array}$ & $\begin{array}{l}\text { Representar ligantes } \\
\text { bidentados em } \\
\text { complemento ao } \\
\text { modelo molecular }\end{array}$ & $\begin{array}{l}\text { Objeto mediador } \\
\text { ressignificado }\end{array}$ \\
\hline
\end{tabular}

Figura 9. Síntese dos meios mediacionais utilizados pelos professores e as transformações que as ressignificações nos seus usos causaram

Destacamos as ressignificações produzidas por Daiane e Mateus ao utilizarem a folha de papel e pedaços de fita crepe para representar, respectivamente, o plano que contém os átomos da molécula em geometria trigonal plana e os ligantes bidentados no complexo inorgânico. Nota-se que todas essas ações tinham como objetivo complementar o uso do modelo molecular. Isso nos faz concluir que a complementação com objetos ressignificados pode ampliar as possibilidades de significação dos próprios objetos mediadores tradicionais, como nos modelos moleculares usados por eles. Ou seja, essas complementações podem diminuir as restrições (Wertsch, 1998) do modelo molecular, 
no entendimento sobre a orientação espacial das ligações e dos átomos, possibilitando novas affordances dos objetos à ação (Gibson, 1986).

Aline, por sua vez, usou um objeto que estava disponível no ambiente, sinalizando que ela não havia planejado esse uso, o que foi confirmando numa entrevista que realizamos com outra finalidade. Ao tomar o objeto como "se fosse" o caderno do estudante, Aline conseguiu estabelecer uma relação intersubjetiva com eles. Essa relação reforçou a forma como usar a regra e a contra-regra, pois ela provavelmente direcionou o olhar dos estudantes para as ações que eles deveriam, ou não, realizar quando estivessem com as fórmulas de Fischer desenhadas em seus cadernos. Nesse sentido, ela estava favorecendo situações de educação da atenção dos estudantes (Ingold, 2010).

Por fim, ao usar objetos do cotidiano do aluno (transferidor e fita adesiva) para indicar que os materiais de que eles são feitos possuem atividade óptica, Elvis trouxe esse tema para o dia-a-dia do estudante. Dessa maneira, as ressignificações, tanto do retroprojetor quando do transferidor e da fita adesiva, auxiliaram o processo de contextualização da Física de curso superior.

Quando consideramos o professor agindo com meios mediacionais, isso exclui qualquer tendência em analisar parcialmente, ou separadamente, as contribuições que são produzidas pelo professor e as que são produzidas pelos recursos. Por exemplo, quando Elvis manipulou objetos no retroprojetor, o aparato experimental foi incapaz de possibilitar, sozinho, o entendimento dos conceitos abordados na ação. Por outro lado, sem os objetos mediadores citados, talvez o professor tivesse dificuldade em discutir os conceitos, ou até mesmo, não conseguisse ensiná-los e atingir os objetivos programados. Novamente, isso é um exemplo do que Wertsch (1998) denomina tensão irredutível entre agentes e meios mediacionais. Nessa perspectiva, é quase impossível ocorrer qualquer forma de ação mediada sem um meio mediacional adequado e um usuário desse meio com habilidade necessária para manipulá-lo.

\section{Conclusões e implicações}

De modo geral, quando focamos nossos olhares sobre os objetos mediadores ressignificados, percebemos que eles causaram transformações nas ações dos professores observadas durante as aulas. Os objetos mediadores ressignificados utilizados pelos professores ofereceram affordances às ações, na medida em que definiram a dinâmica da aula e possibilitaram e ampliaram a discussão de conceitos.

O ensino de Ciências é promovido, na maioria das vezes, por um conjunto de ações mediadas que são variadas e dependentes de vários fatores, como a formação dos professores, o planejamento prévio das aulas, a disponibilidade de recursos, o espaço físico e a sensibilidade do professor. Esses fatores garantem a idiossincrasia das ações em situações de ensino em salas de aula. O professor, os meios mediacionais e os estudantes assumem papéis diferenciados, mas ao mesmo tempo interligados. Para que os professores tenham sucesso quando em uso dos meios mediacionais é necessário que eles ofereçam oportunidades reais de produção de sentidos e compartilhamento 
de significados. Mesmo sem investigar a aprendizagem dos estudantes, nem como eles avaliam a performance dos professores, vimos que os professores valorizaram os objetos nas ações ao materializarem fenômenos, como na aula de Física ou elementos espaciais para melhorar a compreensão tridimensional dos aprendizes, importante quando se estudam as propriedades de compostos químicos, como moléculas, em aulas de Química.

Acreditamos que as ações dos professores com os meios mediacionais potencializam a capacidade real dos recursos em participar do processo de construção do conhecimento. Perguntamo-nos, sobremaneira, se esses professores conseguiriam atingir os objetivos de ensino, nessas aulas e abordando os mesmos conceitos científicos, caso eles não fizessem uso das ferramentas, sobretudo, aquelas que tiveram seu uso ressignificado.

Os meios mediacionais, em geral, apresentam significados próprios, incluindo mensagens sobre seu uso. Nos episódios analisados, ao que parece, os professores reconheceram essas mensagens. Além disso, eles recriaram outras, o que garantia as ressignificações produzidas nas ações quando objetos foram usados. A eficácia dessa mediação é dependente tanto do recurso quanto do modo como ele foi manipulado.

Embora as ações dos professores com meios mediacionais descritos neste trabalho sejam eventos isolados do contexto geral das aulas, de um modo geral, essas análises podem ser bastante úteis para evidenciar o poder e a importância e, até mesmo, a complexidade, que o uso de recursos materiais apresenta para a construção de conhecimento. Isso sugere um tema importante para o desenvolvimento profissional de professores, pois essa sensibilidade pode ser educada desde que sejam mostradas possibilidades concretas de uso ressignificado de objetos.

A análise das ações dos professores da educação superior sobre meios mediacionais traz contribuições pontuais, mas importantes, para o entendimento de suas aulas, além de propiciar a discussão e elaboração de diferentes estratégias a serem utilizadas. Esses professores têm a capacidade de transformar ferramentas comuns em outras com significados múltiplos capazes de potencializar o entendimento dos temas científicos introduzidos nas aulas. Ao descrever as formas que caracterizaram os spinoff's realizados por esses professores, fomos capazes de entender as situações em que eles ocorrem e que aprendizagem eles favorecem. Isso só foi possível porque construímos os instrumentos necessários para realizarmos a categorização dos meios mediacionais.

Dessa maneira, sugerimos que a ferramenta de análise apresentada neste artigo sirva como base para pesquisas futuras sobre o uso de meios mediacionais em salas de aula. Diante disso, reconhecemos que ela possivelmente precise ser modificada e adaptada para análises de outros contextos de ensino, vistas as idiossincrasias das ações de professores de ciências com diversos meios mediacionais e as diferentes possibilidades de produção de ressignificações nessas ações.

A formação de professores preconiza que eles tenham domínio de conteúdos e de diferentes estratégias didáticas para ensiná-los, mas não parece ainda considerar o conjunto de objetos materiais disponíveis no ambiente e de modos semióticos que 
potencializam o trabalho do professor. É nesse contexto que julgamos importantes as práticas apresentadas e analisadas neste artigo, pois identificam como o professor pode considerar os objetos mediadores e potencializá-los, na produção de sentidos, por meio da ressignificação. Além disso, acreditamos que usos de recursos materiais e suas possíveis ressignificações podem ser objeto de estudo nos cursos de formação regular ou continuada de professores.

\section{Referências}

Buty, C., \& Mortimer, E. F. (2008). Dialogic/Authoritative Discourse and Modelling in a High School Teaching Sequence on Optics. International Journal of Science Education, 30 (12), 1635-1660. https://doi.org/10.1080/09500690701466280.

Gibson, J. J. (1986). The Ecological Approach to Visual Perception. Front Cover. Lawrence Erlbaum.

Ingold, T. (2010). Da transmissão de representações à educação da atenção. Educação, $33(1), 6-25$.

Moro, L., Pereira R. R., Mortimer, E. F., Araújo, A.C.S., Sá, E. F., Santos, E. P., Silva, P.S., Martins, R. F., Quadros, A. L., \& Azevedo, L. L. (2013). Gestos ancorados em um terceiro modo semiótico: como auxiliam na criação de modelos tridimensionais. In IX Encontro Nacional de Pesquisa em Educação em Ciências - IX ENPEC. Águas de Lindóia, SP.

Mortimer, E. F., Massicame, T., Buty, C., \& Tiberghien, A. (2007). Uma metodologia para caracterizar os gêneros de discurso como tipos de estratégias enunciativas nas aulas de ciências. In R., Nardi. A pesquisa em ensino de ciência no Brasil: alguns recortes. São Paulo: Escritura.

Nakou, I. (2007). Educação Histórica: o uso de ferramentas culturais relacionadas com a diversidade de experiências e atitudes dos estudantes. Currículo sem Fronteiras, 7(1), $137-159$.

Oliveira, L. A. Sá, E. F. \& Mortimer, E. F (2017). Interações de um Professor de Física com Objetos Mediadores e as Ressignificações Produzidas na Sala de Aula. In Atas do XI Encontro Nacional de Pesquisa em Educação em Ciências - XI ENPEC. Florianópolis, SC.

Otero, V. (2003). Cognitive processes and the learning of physics part II: mediated action. Paper presented at the International school of physics "Enrico Fermi": Course CLVI Research on Physics Education, Varenna, Italy.

Tomasello, M. (2003). Origens Culturais da aquisição do Conhecimento Humano. São Paulo, Martins Fontes.

Vigotski, L.S. (2001). A construção do Pensamento e da Linguagem. São Paulo: Martins Fontes.

Wertsch, J. (1998). Mind as action. New York: Oxford University Press. 
Wertsch, J. V. (1991). Voices of the mind: A sociocultural approach to mediated action. Cambridge: Harvard University Press.

Leandro Antônio de Oliveira

(ㄱ) https://orcid.org/0000-0002-5597-3438 Universidade Federal de Minas Gerais Belo Horizonte, Minas Gerais, Brasil leandroquiufmg@gmail.com

\section{Eliane Ferreira de Sá}

https://orcid.org/0000-0002-0115-9799 Universidade Federal de Minas Gerais Belo Horizonte, Minas Gerais, Brasil elianefs@gmail.com

\section{Eduardo Fleury Mortimer}

https://orcid.org/0000-0002-3025-121X Universidade Federal de Minas Gerais Belo Horizonte, Minas Gerais, Brasil efmortimer@gmail.com

Submetido em 09 de Novembro de 2018 Aceito em 27 de Fevereiro de 2019 Publicado em 04 de Maio de 2019 